\title{
Discussion on the Application of Information Teaching Methods in E-commerce Courses
}

\author{
Fang ZHOU
}

Nanyang Institute of Technology, Nanyang City, Henan Province, China

Keywords: Information teaching, Micro-class, E-commerce.

\begin{abstract}
The course of e-commerce needs the support of the Internet because of the particularity of its research field. However, the application of information-based teaching methods in e-commerce courses is undoubtedly a new innovation point. The application of information technology in E-commerce courses helps to improve teaching quality so as to lift the quality of e-commerce talents. This article mainly discusses the application of information teaching methods in e-commerce courses, including the application of "micro-class", task-driven methods in e-commerce courses, and some problems needing attention.
\end{abstract}

\section{Introduction}

With the development of science and technology, driven by the "Internet + " wave, more and more attention has been paid to e-commerce courses. However, the traditional e-commerce teaching cannot meet the e-commerce talent requirements of the business, for it focuses on theoretical teaching, separating theoretical knowledge from practical knowledge. Therefore, in order to provide society with a new type of e-commerce talents, it is imperative to introduce information teaching methods into e-commerce courses. "Micro-class", as an informational teaching method, represents the organic combination of the Internet environment and traditional teaching activities in colleges and universities. Therefore, "micro-class" has been widely used in college e-commerce courses in recent years.

\section{Related Concepts}

\section{Information Teaching Methods}

The so-called "information teaching methods" refers to the Internet-based teaching platform that employs electronic courseware, multimedia, animation teaching, live teaching video and synchronous live teaching as the main carrier. Using information teaching methods in e-commerce teaching process helps to integrate the theoretical knowledge quickly into the actual social tasks, so that students can quickly grasp the theoretical knowledge of e-commerce.

\section{"Micro-class"}

The so-called "micro-class", or micro lecture refers to a teaching method in which the teacher records the teaching of a certain knowledge point or a teaching link in advance, then plays the video in the classroom to improve the efficiency of the teaching resources. The emergence of "micro-class" makes the related courses take on more exhibition forms.

\section{E-commerce Courses}

E-commerce refers to the electronic realization of the entire trading activity, which exists both in a broad sense and in a narrow sense. Narrow e-commerce, also known as electronic commerce (EC), is mainly the use of computer networks for trading activities. Broad E-business (EB) is the use of all kinds of information technology means for all the business management activities. The traditional teaching is mainly the model of teachers lecturing and students listening, which results in lower technical standards of students. Information teaching means can effectively improve students' application ability. 


\section{The Application of Informational Teaching Methods in E-commerce Curriculum The Application of "Micro-class" in the E-commerce Courses}

As a new teaching mode, the application of "micro-class" in e-commerce curriculum reflects four major characteristics: the less curriculum content, short teaching time, small capacity of curriculum resources and flexible use of curriculum resources. Since "micro-class" is mainly a pre-recorded 10-minute video by a teacher for the teaching of a knowledge point or a teaching part, the purpose is to improve teaching efficiency and enrich classroom form and content.

Build Easy- to -operate "Micro-class" Platform. The introduction of "micro-class" to the e-commerce course teaching process requires the operability and convenience of "micro-class" learning platform. For example, e-commerce instructors may be required to upload the video they use or recommend to the campus network learning center for practical guidance as students download it. In addition, the length of "micro-class" should not be too long. It should be controlled within 10 minutes, preferably about five minutes.

Promote the Opening up of "Micro Class" at a Higher Level. E-commerce itself is a course that is highly dependent on information technology, which determines the implementation of "micro-class" should achieve a deeper level of opening up. On the one hand, it is necessary to involve more teachers in the recording of "micro class" to incorporate the ten minutes of "micro class" into the forty minutes in classroom, highlighting the "problem focus" feature of "micro class" to make the classroom teaching even better. On the other hand, students should be fully liberalized. With the increasing popularity of mobile learning, remote learning and online learning, the main battlefield for the construction of "micro class" should be extended to extracurricular activities to make it a shared teaching resource and meet students' independent study and inquiry learning and other personalized needs.

Enhance the Attractiveness of "Micro Class". "Micro-class" brings about a completely different feeling of learning: it can mobilize all the senses such as vision, hearing, imagination and others to participate in learning, with sophisticated, practical and efficient features; it can be played anytime and anywhere, so it is flexible to use; the content is targeted, inspiring; formally, it is lively and very attractive. Many "micro-classes" consist of texts, dubbing and pictures as well as easy, casual voiceover and creates a relaxed atmosphere for teaching; reading concise texts instead of commentaries. It attracts students' attention whether it is collective training or self-study. Finally, teachers should also focus on strengthening the interaction between teachers and students, understand what the students really need, and encourage students to ask questions about the issues encountered in e-commerce in the "micro class" platform and classroom and give timely answers to mobilize the learning enthusiasm of the students.

The Application of the Task-driven Approach in E-commerce Courses. Task-driven pedagogy refers to the process of learning information technology in which motivated students focus on a common task activity with the help of teachers, actively sort out and apply their learning resources for independent exploration and interactive learning. In this process, students will also continue to gain a sense of accomplishment, which can greatly stimulate their desire for knowledge and gradually form a virtuous cycle of perceptual mental activity, so as to cultivate self-learning ability to explore independently and forge ahead courageously.

Assignment and Arrangement of Tasks. In the first week of each semester, the tasks should be clearly assigned. Students should be informed of the specific tasks, the criteria for completion and the means of assessment so that they can start learning with the tasks. Since a task consists of several smaller tasks, it may be difficult for a single student to complete it in a semester. The task requires a class of students to be divided into groups of no more than 6 students, each of whom does assignments and interacts with one another, to accomplish specific tasks. Specific course tasks must include the task of theoretical knowledge, the task of the practice part and the task of combining the two.

Advantages of Task-driven Approach in the E-commerce Curriculum. (1) Improving students' learning initiative. The task-driven approach allows students to change the original passive 
learning, fully mobilize their enthusiasm, and take the initiative to participate in the study and discussion so as to improve their learning efficiency.

(2) Improving students' practical ability. In terms of student feedback, by completing the task, students can independently get access to information, complete the production of PPT, independently register a store, give it a simple decoration and operate it so that they can greatly improve their application ability.

(3) Enhancing students' ability of innovation and entrepreneurship. The task-driven method enables students to carry out the task with each question so that students can improve their ability to think independently and solve problems, which is also an essential quality of thinking with innovative entrepreneurship and will lay a very solid foundation for students to enter the society later.

\section{Several Issues that should be Paid Attention to in the Application of Information Teaching Methods in E-commerce Courses}

\section{To Choose the Appropriate Information Teaching Projects}

E-commerce is a practical course. In choosing appropriate informational teaching projects, it should be apt to use those projects that are practical and fit for the actual social practice. The "micro-class" and task-driven approach mentioned in this article can be used as a reference for information teaching project. When choosing the project, it should be compatible with the e-commerce teaching module. If the teaching is focused on the application of e-commerce technology, we should attach importance to the website construction and web design art in the project selection process. If the teaching is focused on business, then attention should be paid to the enterprise's product management, sales management and customer management and other aspects while choosing the project.

\section{To Clarify the Relationship between Teaching Focus and Information Means}

E-commerce itself requires the use and the integration of online resources. How to clarify the relationship between teaching priorities and information means is what we should pay attention to in the implementation process. In the process of teaching, it is easy for some students to just finish the progress in order to complete the information-based teaching task, and neglect the theoretical knowledge contained therein. For example, in a project where an individual opens an online shop, some students choose a brush credit method that violates the platform regulations in order to upgrade their store level. Although it can make the store's credit rating rise, it ignores the legal rules of the platform, which will lead to the loss of their professional ethics. Therefore, this kind of operation behavior is not advocated and approved. In the personal shop management process, teachers need to sort out the theoretical knowledge in a timely manner so that students can maintain a healthy development, and use the rules to carry out legitimate competition.

\section{To Strengthen Teaching Guidance and Supervision}

In the process of informatization teaching, the role of teachers is to assist and guide students. This means that while teachers understand the theoretical knowledge of e-commerce, they are supposed to plan and arrange the projects well and predict the problems students may encounter during the teaching process in order to formulate the corresponding solution. In the process of teaching, they should also adjust their teaching plans in a timely manner according to the actual satate of the students so as to ensure that the project teaching can be completed quickly and accurately. At the same time, teachers also play a supervisory role in the whole process, supervise and prevent "free riding" in the grouping, supervise the whole process before class, in class and after class, and eliminate the phenomenon that students usually do not do anything about the task and then copy the achievements of other team members upon handing in their task. 


\section{Conclusion}

In short, informational teaching methods are worth popularizing in e-commerce specialized courses teaching. Through informational teaching methods, the learning objectives for the students can be clearly defined, their learning dynamics can be clearly understood, and the theoretical knowledge of e-commerce can be effectively combined with the actual operation, which improves teaching efficiency and thus helps to cultivate high-level e-commerce talents for the society.

\section{References}

[1] Mohammad, Jehangir Khan, Dminic P, Dhanapal Durai, Alan, G. Downe, Alamgir, Khan. Human Resourses Impact on Business Performance: An E-commerce Capability Approach [R].Britain:2010 Iternational Conference on Intelligence and Information Technology, 2011

[2] Sushil K.Sharma .Socio-Economic Impact and Influence of E-commerce in a Digital Economy [M].USA: Idea Group Publishing, 2005.

[3] Sameni, Mahta K, Analysis of Human Resource Development for Information Technology and E-commerce in Iran [R].Tehran: Technology management for the Global Future, 2006. 